\title{
Status of the PSR Improvement Program*
}

\author{
R. I. Macek, D. H. Fitzgerald, M. Hochn, R. Ryder, and R. York \\ Medium Energy Physics Division, Los Alamos National Laboratory, Los Alamos NM. 87545
}

Ahstract

A program of improvements to increase intensity and improve reliability of the Los Alamos Proton Storage Ring (PSR) has been under way for several years. Reduction of stored beam loss rates by a factor of 4.6 since 1987 through exploitation of $\mathrm{H}^{\circ}$ injection has allowed the average intensity to increase by a factor of two to $75 \mu \mathrm{A}$. Reliability of the PSR and associated beam delivery systems has been improved by ixtensive rework of numerous subsystems. Radiation protection has been improved by additional shielding of L.ine $D$ and extensive use of relatively fail-safe radiation detectors incorporated into an inproved radiation securiiy system.

\section{INTRODUCTION}

PSR was designed as an $800 \mathrm{MeV}$ pulse compressor ring to accumulate a large fraction of a L.AMPF inacropulse (-800) $\mu \mathrm{s})$ and provide short $(0.25 \mu \mathrm{s})$, intense pulses to a spallation neutron target. After two years of commissioning and initial operation. the limitations on performance due to beam losses and hardware reliability were evident. Radioactivation of the ring components limited the average current to about $30 \mu \mathrm{A}$. Peak intensity was and still is limited to $\cdots .3 .5 \times 10^{13}$ protons per pulse by a transverse instability, now thought to be caused by coupled e-p oscillations. [1] concerns about the adequacy of the shielding required exclusion of users tron the I.ANSCl: (l.os Alamos Neutron Sicattermg (enter) experimental hall (I:R-I) when beam was oll. ()verall beam availability on target was $55 n_{0}(1988)$ and judged to be inadequate for a national users program.

Hy 1988, the mechanisms for the stored beam losses had been identitied, the potential for significant improvenent recognized, and an improvement program initiated which had as its main gonls satc, reliable, $10(0)-\mu \Lambda$ operation at $2(0-11 /$. repetition rale. I.cinger term, llere wiss the possibility Io

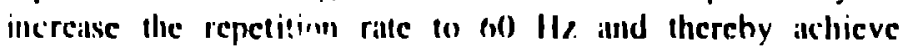
iverage currents (1) (0 $3(1)(0) \mu \mathrm{A}$.

\section{INTIEN:ITYY IMPROVIIMI:NTS}

lhe initial intemsty upgrade plan was to tirst explosit II" injecton by a mumber of incremential improvements and an "preride of the $1 f^{-}$ion source helore undertaking more limdament.: . : Inl cosily changes Io PSR injection or the full aperture cxtrinction uperiade.

Injection imto IPSR is a Iwo-step processis, as depicfed in

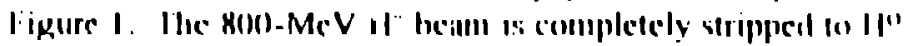

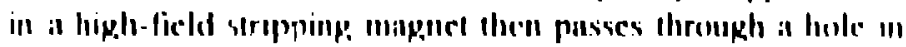

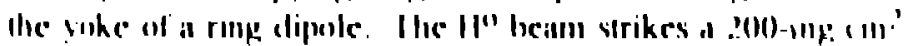

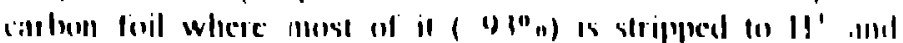

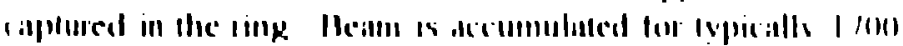

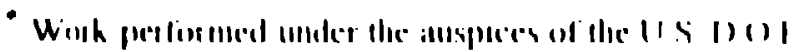

lums and extracted in a single tum.

\section{f. Beum Losse's}

The requirement for hands-on-maintenance limits localized losses (over distances of - $1 \mathrm{~m}$ ) in about 100 ) -200 nA average. For the loss patterns in PSR. this implies heeping the total losses to less than $50 \mathrm{n}_{\mathrm{nA}}$.

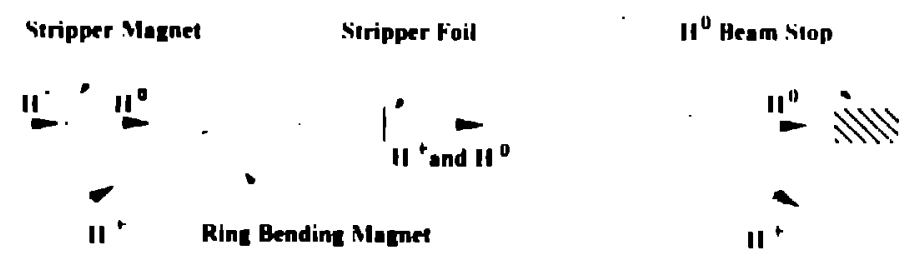

Figure I. Layout of injection region in the PSR.

The "slow" beam-loss current is well described by iwo terms: a constant term (Ist turn) proponional to the injected current, $I_{\text {in }}$ and a term increasing linearly in time and proportional to the stored beam current. $I_{\text {in }} \cdot N(t)$, where $N$ is the number of turns injected. The losses of $0.2-(0.3 \%$ on the lirst tum after injection are now thought to be predominately caused hy production of excited states of II" with principle "uantum number $\geq 3$, which subsequently strip part wily through the fringe field of the first dipole downstream of the stripper foil and fall outside the acceptance of the ring. [2] Stored heam losses arise primarily from nuclear and coulonb scattering of the protons through repeated triversals of the stripper foil and from the increase in heam si/e due to lle increase in momentum spread produced by action of the $\mathrm{Rl}$ : huncher. [3]

The key to reducing the stored beam losses is to minimize heam scaltering at the stripper foil. Most options for increasing the current ain to reduce the number of timess the stored protons hit the foil; many use: an improved schems of plase-space "pninting" at injection to redace toil hits.

\section{Avploitution of II" Injection}

()tfere injection in the verticial plank: a xploited the untillad

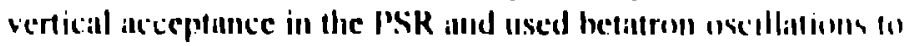

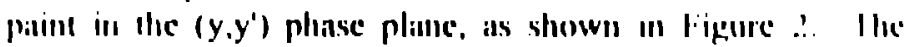
stripuer foil material necel only cover lhe aren of the If" he'inn.

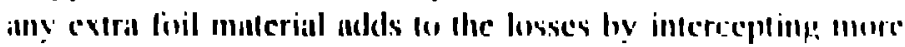
111 the stored benm. Fo exploit this ideil. in mimimum areis

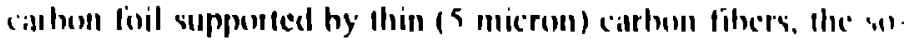

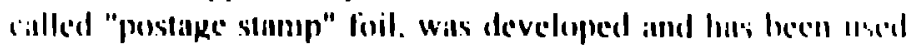
successfiully fur severnl years.

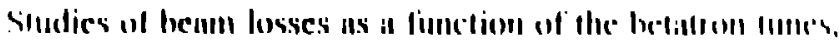

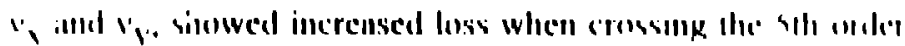

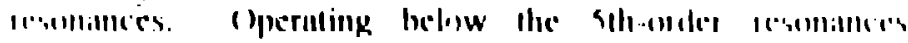

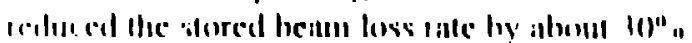

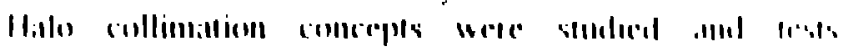

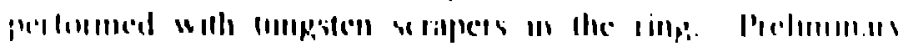


results were discouraging. Two problems were recognized: (1) Scattering from the edges of the scraper collimator produces losses elsewhere; thus, for collimators to be beneficial, slit scattering must be less than the losses prevented elsewhere by the collimator. (2) A good optics location for the collimator, where the limiting aperture (septum magnet) is shadowed by a dispersion-free image of the colimator, was not found in the existing lattice.

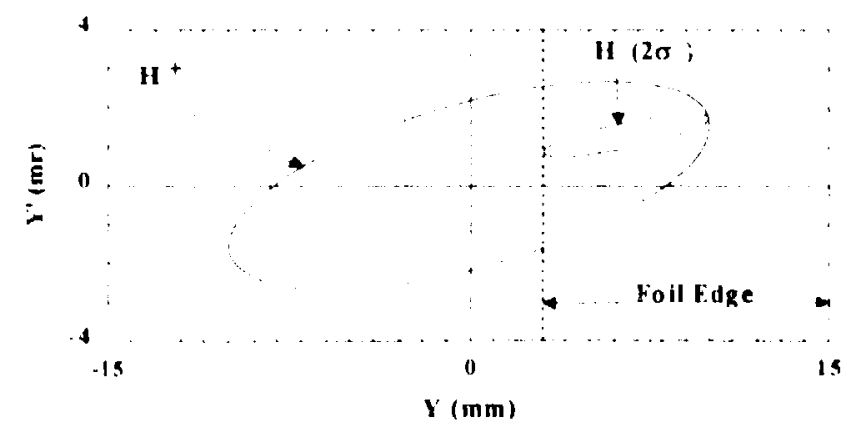

Figure 2. Y.Y' phase-space eliipses at the stripper foil.

Reductions in the stored bean-loss rate for various measures implemented since $1 \%_{07}$ are listed below.

\section{Measure}

Vertical Offset Injection

"Postage Stamp" Foil

lower ()perating Point

Miscellaneous Improvements

Overall Improvement

\section{(: It Ion Sourie' lipgrade}

Injection of higher peak current into the PSR will reduce the number of turns needed to accumulate a given charge and the number of foil iraversals. Development of a volume $11^{-}$ source with twice the peak intensity and half the emittance of the present cusp-field source was judged to be feasible and considered to be the most cost-effective next step toward increased intensity. It has the added benefit of reducing the linat: daty fictor needed to serve the I.ANSCI: program. A major effort is under way at los Alamos to test and evaluate (wo pomising options (a design from Berkeley and a version at the HNI design engeneced for high duty factor operatton) and the ase of RI to excite the source plasma. Results to dite ar encouraping, detatis can be fourd in a companion paper al this conterence $|+| \mid$

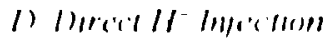

The If" ingection methes an tire PSR suffers from livo

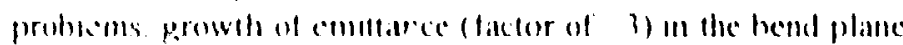

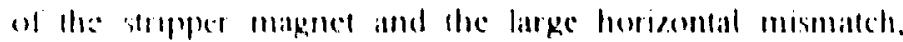
which arrees from lemelamental consttaints fomball beam spot

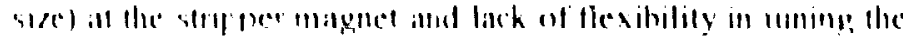

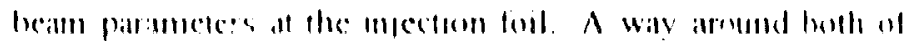

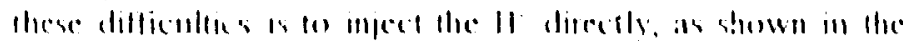

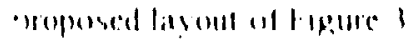

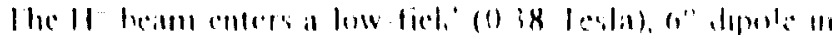

the ring at a position and angle such that it will emerge on the same trajectory as the stored $\mathrm{H}^{+}$beam. A foil stripper to convert $\mathrm{H}^{-}$to $\mathrm{H}^{+}$follows. Bump magnets in the ring provide a programmed closed-orbit bump for optimized injection painting. Some $\mathrm{H}^{\circ}$ will emerge from the stripper foil: in addition, some $\mathrm{H}^{-}$will miss the foil and be stripped to $11^{\circ}$ in the fringe field of the ring dipole. Provisions are made to transport both $\mathrm{H}^{\circ}$ beams to the existing $\mathrm{H}^{\circ}$ dump. Of all the upgrades considered, the direct $\mathrm{H}^{-}$injection ontion was expected to provide the greatest reduction in beam losses, but lack of funding has prevented its implementation

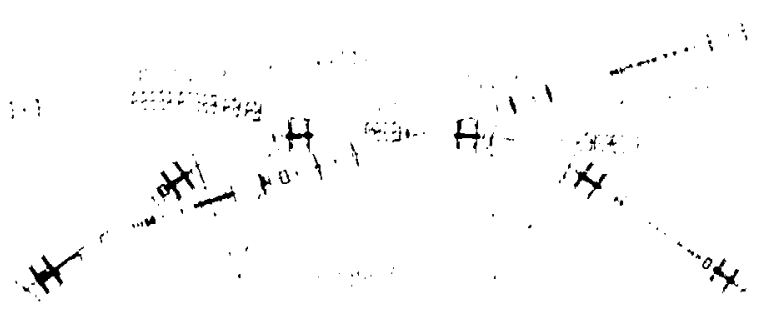

Figure 3. Layout for direct $\mathrm{H}^{-}$injection.

\section{E. Full-Aperture Extration}

The horizontal acceptance of the PSR is limited by the existing extraction system; $50 \%$ more horizontal aperture ( 2 times larger horizontal phase space acceptance) is arailable with more powertul extraction kickers. The larger aperture would have three main advantages: more of the beani scattered in the foil can be captured, thus reducing losses: injection painting can be made more effective in keeping the beam uft the foil with either $\mathrm{H}^{\circ}$ or direct $\mathrm{H}^{-}$injection: and the increased horizontal beam size will reduce the heam density and associated space-charge effects.

$R \& D$ ) was started on a ferrite kicker system that wornld provide the larger kick needed for full-aperture extraction. A prototype pulser was designed and fabricatton begun but wats halted just short of complition for lack of funds.

\section{RADIATION PROTIE("TION IPP(TRAI)IS}

Shiclding and radiation protection issues have been anmong the most difficult problems to solve, in part heciuse of the difficulty in developing lasting criteria in an environment of changing, standards, but also hecaluse shiekding retrotits are very difficult and expensive in the hiphly buth up are .tomend

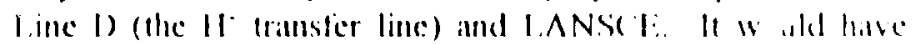
been far easier and less costly 60 provide more shichling. wh the intial construction at the green-field site

the problems originate with the critertal lased lon

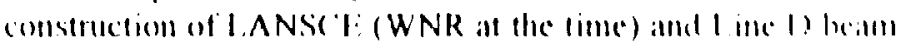
rameport which was based on desipn losses of $1101.411 .4 \mathrm{~m}$

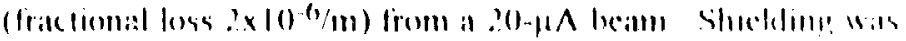

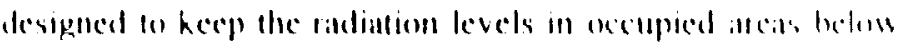

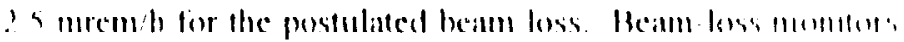

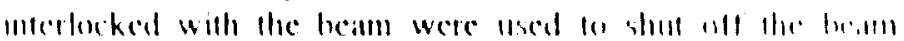

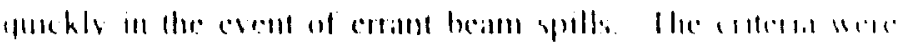

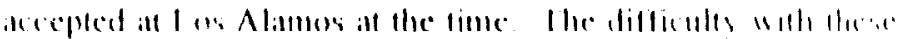

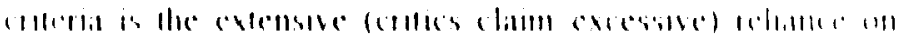


instrumentation to prevent lethal doses in the event of a worstcase, tull-power beam spill. Most of the shiclding was not upgraded with the advent of the PSR and an upgraded WNR. Should the instrumentation fail during a full-power spill, dose rates as high as $10-50 \times 10^{3} \mathrm{rem} / \mathrm{h}$ are possible in sccupied areas for indeterminate lengths of time.

Improvement of radiation protection systems procseded on several fronts. Reliability of the active protection system was greally enhanced by the development and implementation of a three-layered radiation interlock system consisting of failsafe team-current limiters for the normally low-current portions of Line D, tail-safe spill monitors for all beam tunnels, and neutron radiation detectors in occujied areas. These were incorporated into an improved radiation security and beam shut-off system. L.AMPF prompt radiation protection criteria were developed that called for a non-lethal cap on the maximum potential dose's possible in occupied areas under worst-case accident scenarios, including failure of all the protection instrumentation. A comprehensive shielding assessment was undertaken, which included extensive beamspill tests of shielding effectiveness. Most important!y, major augmentations of the shielding were implemented in Line-I) where it passes over the LANSCF experimental room (E:R-1) and in the region around the proton beam transport (11. Line) just before the beam enters the LANSCF target (see Figure 4). More shielding was added over the l.ine-I) tunnel under a iseavily traveled road, and at the $I$, ine- $D$ ) entrance maze to the beam switchyard.

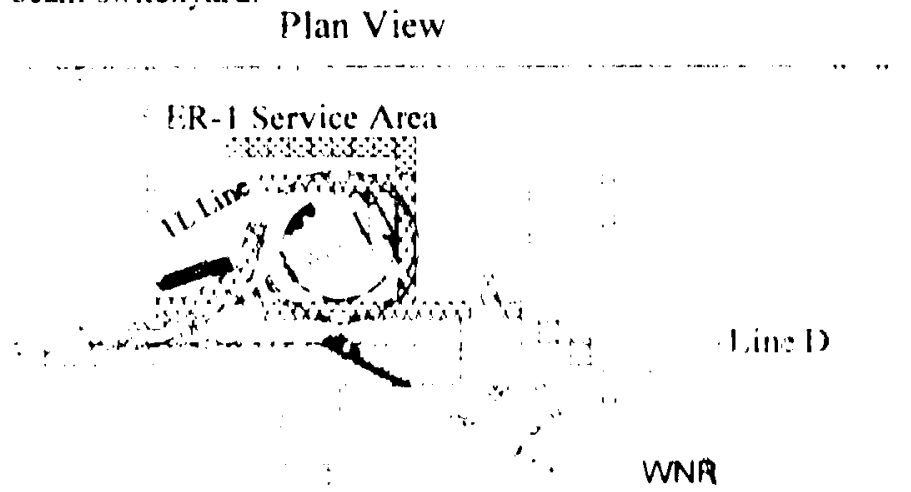

likvation View

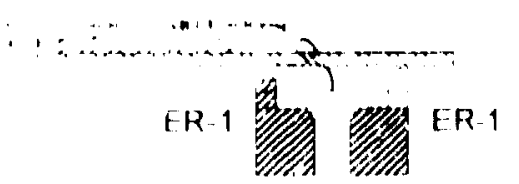

ligure a I ANSid 1 targed cell shichding

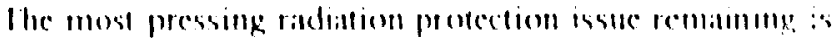

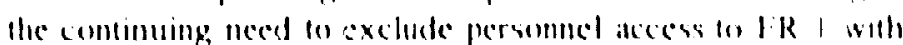

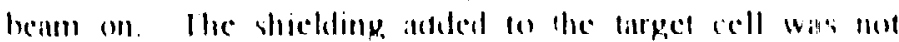
surficient to reduce the poremtial levels in l $R$ - 1 from at lull

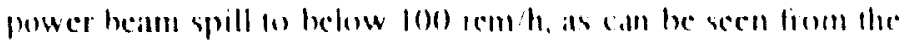

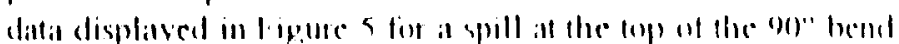

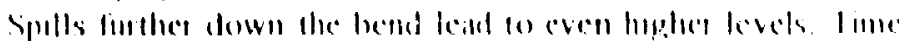

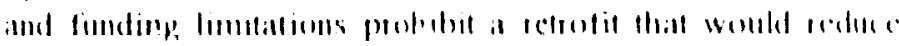

the potential hazard to levels that permit occupancy while beam is on.

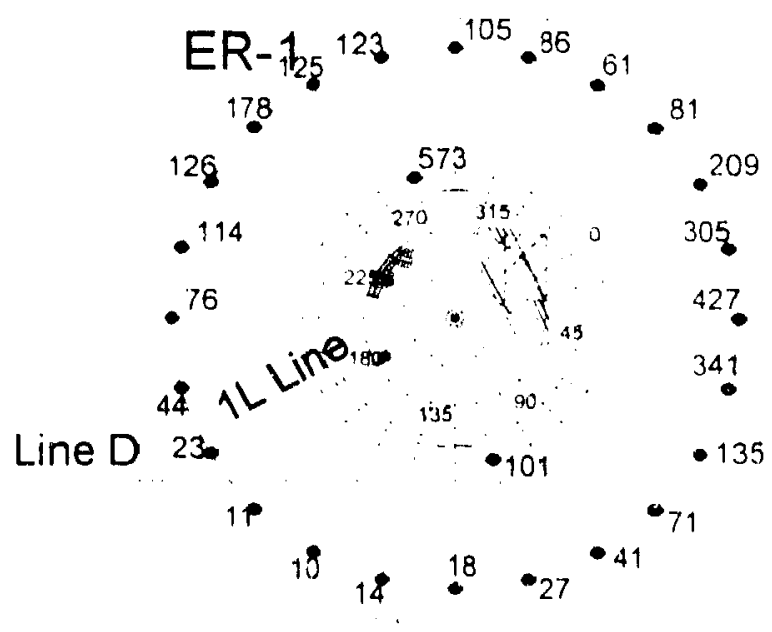

Figure 5. Radiation levels $(\mathrm{rem} / \mathrm{h})$ in ER-I from a fiuilpower spill (from data scaled to a $100 \mu \mathrm{A}$ spill).

\section{JV. RELIABILITY/AVAII ABIIITYY}

Availability of the PSR and the L.ANSCE: heam delivery systems has improved greatly since 1988 through extensive rework of numerous subsystems, including magnet power supplies, deionized water, vacuum, pulsed power, beam diagnostics, and computer controls systems. Overall availability of beam (including the linac) to the users rose from $55 \%$ in 1988 to $75 \%$ in 1989 but has declined $10 \quad 65^{\circ} 0$ in the past two years, primarily hecause of declining ivirilibility of the linac. The situation is complicited but is essentially caused by funding shortalls for the I.AMPl nuckear physics program, which funds the operation of the linate

\section{V. (')N('IIISIONS}

We conclude that there are no technical barriets in reliable. 100 \#A operation of PSR which is Ihe sime conclusion reached by the external PSR Review Boird. Ihe menu of proposed improvements contans enough to reath the foal. We acknowledge the contributions of the entere perk development and operations staff in the progeress to date

\section{RIITIRINNCIS}

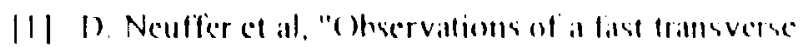
instability in the PSR". Nud. Instrum, Meth $A$ 'l (10u)? ple. 1-1?

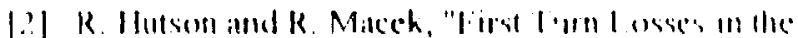

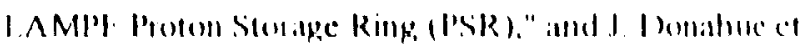

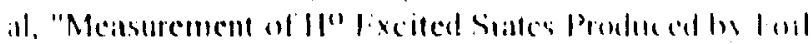

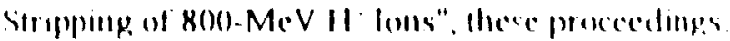

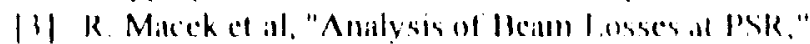

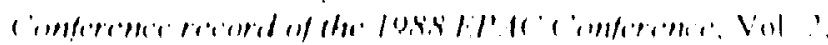
lll 1.9? 1:25.4

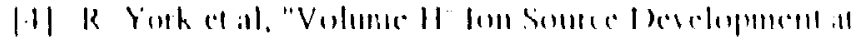

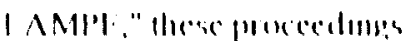

